\title{
A Case of Military Munchausen's Syndrome
}

\author{
Sqn Ldr J E Hambidge \\ FRCS (Ed), RAF*
}

\author{
Wg Cdr D R Richardson \\ FRCS, RAF \\ Consultant Surgeon \\ Surgical Division, Princess Alexandra Hospital Royal Air Force Wroughton, Swindon, Wilts.
}

SUMMARY: Since its initial description in 1951 many varients of Munchausen's Syndrome have been described. This present case report is of a patient who adopts military rank in order to gain admission to a service hospital: a case of Military Munchausen's Syndrome.

\section{Introduction}

Munchausen's syndrome is an uncommon factious illness. First described by Asher in 1951(1) three main variants were recognized; abdominal, haemorrhagic and neurological. O'Shea in 1984(2) proposed seven characteristic features which include convenient collapse, signs of previous cut downs and laparotomies and absence of a referral letter together with a plausible past medical history at hospitals a great distance away and immediate self discharge on confrontation. Since the original description many other varients have been recognized(3); these include mania operative activa(4), Munchausen's by proxy(5), jet set Munchausen's(6) as well as gynaecological(7) and psychiatric(8) varieties.

The following case report is of a patient who displays many of the classical features of Munchausen's Syndrome but who also demonstrates several unusual features including a propensity for military hospitals.

\section{Case Report}

At $18.00 \mathrm{hrs}$ the duty surgical registrar received a telephone call from a male with a heavy mid European accent. He claimed to be a consultant surgeon from Germany and to be calling from Swindon railway station. A travelling companion of his, a 31 year old serving Lieutenant Commander in the German Army, had collapsed after a haematemesis. He was now complaining of severe abdominal pain and it was believed that he had perforated a duodenal ulcer. $\mathrm{He}$ requested emergency admission for the officer but was advised to contact emergency services.

At $18.15 \mathrm{hrs}$ a further telephone call was received; the patient had been dispatched in a taxi for admission. The doctor went on to describe how the patient was a known case of Zollinger-Ellison syndrome who in the past had undergone several laparotomies for perforations of duodenal ulcers. He further described how the patient was diabetic but had received no insulin for 24 hours.

At $18.45 \mathrm{hrs}$ a taxi arrived at reception bearing a shabbily dressed man of about 30 whose clothes bore no signs of blood. He appeared to be in pain and was taken directly to the ward for admission.
The patient gave the same basic history as had been given by telephone. He claimed to be travelling from his home in London with his doctor to visit a friend in Dublin but had been taken ill on the train. He had no means of identification as these were in his luggage in Swindon. His escort was travelling on to Dublin alone. He further claimed to be on extended compassionate leave from the German Army following the death of his family in a road traffic accident. He could not explaiño how he came to be resident in Britain.

The patient gave his present symptoms as epigastric pain, nausea and shortage of breath. On examination $h$ was anaemic but not shocked, he was apyrexial and not dyspnoeic. Abdominal examination revealed a long midline scar, generalized tenderness but withou? guarding. He had multiple venepuncture and cut dow marks on both arms. A femoral stab was used to obtai blood samples and an intravenous infusion sited with difficulty. Investigation revealed him to have a hypochromic microcytic anaemia at $10.4 \mathrm{~g} / \mathrm{dl}$ and to be normoglycaemic. Other investigations including chest and abdominal $\mathrm{x}$-ray were unremarkable.

Details of the patient's rank, military training and his previous units together with his address in London proved inaccurate. When challenged by the duty consultant that his story was a fabrication he removed his own Venflon and took his own discharge.

Further investigation revealed that the same patient had presented to the Princess of Wales Hospital, Royal Air Force Ely nine months earlier. Posing as a German civilian he had been taken to casualty from the railway station by taxi. He gave a history of a haematemesis and was complaining of severe abdominal pain. He again claimed to have Zollinger-Ellison syndrome but not diabetes. On examination he was noted to have a long midline abdominal scar from previous laparotomies; his abdomen was noted to be generally tender with rebound guarding. $\mathrm{He}$ had normal haematological and radiological findings.

The patient was prepared for and underwent a laparotomy through the previous incision. Multiple adhesions were encountered and divided. When a naso-

* Now Senior Specialist in Orthopaedic Surgery, Princess Mary's Royal Air Force Hospital, Halton, Aylesbury, Bucks. 
gastric tube was passed normal gastric aspirate was found. At this point the abdomen was closed. On the third postoperative day the patient took his own discharge.

Two weeks after the Wroughton admission the same patient presented to the Queen Elizabeth Military Hospital, Woolwich. He presented as a Sergeant-Major in the German Army. He again claimed to have had a haematemesis and was now complaining of severe abdominal pain. He gave a history of Zollinger-Ellison syndrome but not diabetes. His guise was discovered by the reception staff and though he was seen by a medical officer no notes were made. He was taken into custody by Ministry of Defence and then civilian police. He remained so convincing that police surgeons were summoned to examine him. He was released without charge the next day.

Investigation by Ministry of Defence and civilian police later revealed the true identity of the patient who is indeed a German citizen living in London. He has a German military and criminal record. He has had no formal medical training and his medical history is unknown.

\section{Discussion}

Though undoubtably suffering from Munchausen's syndrome, he displays at least four of O'Shea's criteria, he does present some unusual features of this diverse condition. It is known that international boundaries do not deter Munchausen patients and hence the presentation of a German national with this condition at a British hospital is not of note. It may be suggested that his obvious linguistic difficulties have led him to adopt abnormal illness behaviour due to an inability to use more conventional channels of communication.

One unusual feature of this case is the patient's self referral. In the two phone calls received, presumably from the patient in the guise of his doctor, he displayed a sound .clinical knowledge of his assumed medical condition and its management. One feature of presentation which may arouse suspicion, especially in a service hospital, is the lack of a referral letter or telephone call. Self referral in the guise of a doctor overcame this potential problem.

The Princess of Wales Hospital, Royal Air Force Ely acts as a district general hospital and his admission there may have been fortuitous as he is known at many other civilian hospitals in the area. His admission to Princess 3 Alexandra Hospital, however, appears to be $\stackrel{\varnothing}{2}$ premeditated. The patient is not known at Princess $?$ Margaret Hospital, Swindon - the local district generalo hospital, nor has the patient presented there since. In order to persuade a service hospital to admit him he $\overline{\bar{G}}$ assumed military rank and employed the unusual tactic of telephoning the target hospital. His subsequent visit $\frac{C}{0}$ to a service hospital was again premeditated. He again $\overline{\bar{\omega}}$ assumed military rank and although he did not $\overrightarrow{\widetilde{\sigma}}$ telephone the hospital he is not known at surrounding civilian casualty units.

The selective use of military hospitals by a civilian $\vec{\circ}$ patient with Munchausen's syndrome has not been $\overrightarrow{-}$ previously described. It is suggested that previous experiences prompt abnormal illness behaviour in the form of Munchausen's syndrome. It may be that this patient's military experience has led him to develop his prediliction for military hospitals.

This case report once again illustrates the ingenuity of patients with Munchausen's syndrome and the distances $\varphi$ they are prepared to travel in order to satisfy their need $\overrightarrow{0}$ for medical attention. This patient took the unusual step 음 of referring himself in the guise of a consultant surgeow to reinforce the validity of his claim to illness. He al\$ assumed military rank in order to pursue his propensi⿺ for service hospitals - a case of Military Munchauser $\mathbb{R} \frac{\mathbb{Q}}{2}$ syndrome.

\section{REFERENCES}

1. ASHER R. Munchausen's Syndrome. Lancet 1951; 26: 339-351.

2. O’Shea B, McGennis A, Cahill M, Falvey ग丁. Munchausen's Syndrome. Br J Hosp Med 1984; 31: 269274.

3. ENOCh M, Trethowan W, Barker J. Some uncommon psychiatric syndromes. Wright (1967), Bristol.

4. Strongmeyer G. Erfahrungen uber lokalneurosen. Rumpler (1873), Hannover.

5. MEADOw R.: Munchausen's Syndrome by Proxy. Lancet 1977; 8033: 343-345.

6. Addison T E, TALAN K H. Jet Set Munchausen syndrome N Eng J Med 1974; 291: 1195.

7. Hustead R M, LeE R A, Maruta T. Factitious illness in Gynaecology. Obstet Gynecol 1982; 59: 214-219.

8. Cheng L, Hummel L. The Munchausen syndrome as a psychiatric condition. Brit J Psychiatry 1978; 133: 20-21. 